\title{
ANÁLISE DA DESIDRATAÇÃO DE RESÍDUOS DE PROCESSAMENTO DE MARACUJÁ (Passiflora Edulis) UTILIZANDO AR QUENTE
}

\author{
T. C. da SILVA ${ }^{1}$, L. V. D. FREITAS ${ }^{1}$, L. M. RODRIGUES ${ }^{1}$, N. C. da SILVA ${ }^{1}$, \\ C. R. DUARTE ${ }^{1}$ e M. A. S. BARROZO ${ }^{1}$ \\ ${ }^{1}$ Universidade Federal de Uberlândia, Faculdade de Engenharia Química \\ E-mail para contato: thaise.c_s@hotmail.com
}

\begin{abstract}
RESUMO - O Brasil é hoje, um dos três maiores produtores de frutas do mundo. Como consequência, tornou-se um dos maiores produtores de resíduos agrícolas. Estes resíduos geralmente são descartados, o que cria certo problema, pois estudos têm mostrado que estes podem apresentar compostos, como vitaminas e antioxidantes, os quais são benéficos para os seres vivos. Conjuntamente, a desidratação têm se mostrado uma forma simples e eficiente de conservação de alimentos sendo que este presente trabalho mostra que a utilização de ar quente e secador leito fixo na desidratação dos resíduos do maracujá pode ser uma alternativa viável, uma vez que o equipamento é de fácil operação e se mostra eficiente quando analisado o efeito das variáveis de processo sobre as propriedades antioxidantes do resíduo.
\end{abstract}

Palavras-Chave: ar quente, leito fixo, antioxidantes, desidratação.

\section{INTRODUÇÃO}

O Brasil atualmente encontra-se como um dos líderes mundiais de produção de frutas. Entretanto, calcula-se que, do total de frutas processadas, sejam gerados, na produção de sucos e polpas, $40 \%$ se tornam resíduos agroindustriais (Bartholo, 1994). Esses resíduos possuem em sua composição vitaminas, minerais, fibras e compostos antioxidantes importantes para as funções fisiológicas. (MATIAS et al., 2005). Deste modo, faz-se necessário o aproveitamento desse material, seja como ração animal, adubo natural ou fonte de alimentos para farinhas.

O maracujá (Passiflora edulis) é uma fruta típica da América Tropical, cuja polpa é muito utilizada na fabricação de suco concentrado. Esta fruta apresenta elevadas taxas de acidez e ácido ascórbico, bem como de compostos fenólicos, o que torna seu resíduo interessante para ser reutilizado na alimentação.

A tecnologia de desidratação escolhida foi a de ar quente em leito fixo. A desidratação por ar quente tem sido um dos mais populares métodos de remoção de umidade de alimentos, sendo que sua instalação, manutenção e controle são bastante simplificados e tem gerado resultados bastante satisfatórios (DUZZIONI et al.,2013). 
Dessa forma, o presente trabalho investiga os efeitos das variáveis do processo de secagem do resíduo do maracujá em leito fixo, tendo em conta a qualidade final do resíduo, em relação às mudanças no conteúdo de ácido cítrico, ácido ascórbico, do total fenólico e flavonoides, e avaliando sua viabilidade com tal método de reutilização.

\section{MATERIAIS E MÉTODOS}

O resíduo de processamento de maracujá foi fornecido pela empresa Lotus Soluções Ambientais, localizada na cidade de Araguari-MG.

A desidratação do material foi realizada em um secador do tipo leito-fixo, utilizando-se a metodologia da camada fina, onde cerca de $170 \mathrm{~g}$ da amostra eram colocadas em uma célula de $180 \mathrm{~mm}$ de largura por $27 \mathrm{~mm}$ de altura a qual possuía telas metálicas em suas duas extremidades para facilitar a passagem homogênea do ar quente. A figura abaixo ilustra todo aparato experimental, que consiste basicamente em um soprador(2), um aquecedor elétrico por resistência(3), acoplado a um variador de voltagem(4), termopares previamente calibrados(6), válvulas gaveta para controle de fluxo(1), medidor de vazão do tipo anemômetro de fio quente(5) e a célula de medida anteriormente explicada.

Figura 1 - Aparato Experimental

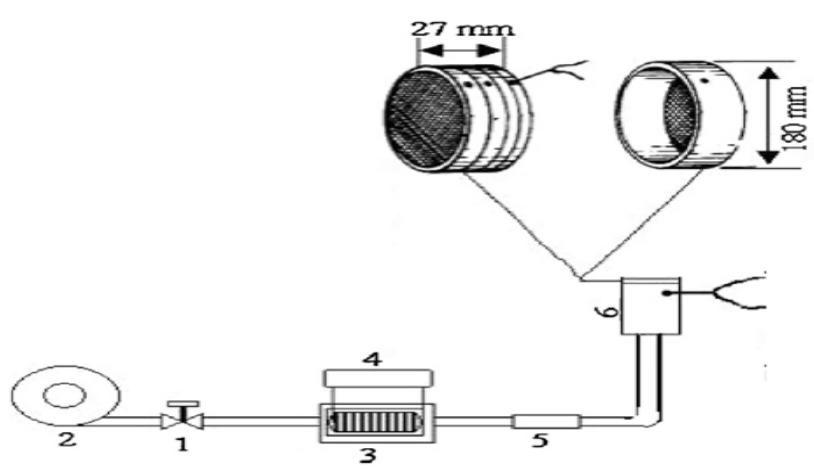

As variáveis observadas durante o processo de desidratação foram velocidade do ar quente, temperatura e tempo de desidratação, organizadas em um planejamento fatorial de dois níveis $\left(2^{\mathrm{K}}\right)$, totalizando 8 experimentos, conforme podemos observa na Tabela 1:

Tabela 1 - Planejamento Experimental

\begin{tabular}{|c|c|c|c|}
\hline Experimento & Velocidade (m/s) & Temperatura ( $\left.{ }^{\circ} \mathbf{C}\right)$ & Tempo (horas) \\
\hline 1 & 1,0 & 50 & 5,0 \\
\hline 2 & 2,0 & 50 & 5,0 \\
\hline 3 & 1,0 & 80 & 5,0 \\
\hline 4 & 2,0 & 80 & 5,0 \\
\hline 5 & 1,0 & 50 & 7,0 \\
\hline 6 & 2,0 & 50 & 7,0 \\
\hline 7 & 1,0 & 80 & 7,0 \\
\hline 8 & 2,0 & 80 & 7,0 \\
\hline
\end{tabular}


Ao término de cada desidratação e visando uma melhor representação dos dados, a taxa de retirada de umidade foi explicitada em termos de um adimensional de umidade denominado MR (moisture ratio), calculado de acordo com a equação 1:

$$
M R=\frac{M-M_{E Q}}{M_{0}-M_{E Q}}
$$

Onde $\mathrm{M}$ é a umidade em cada ponto, $\mathrm{M}_{0}$ é a umidade inicial do material e $\mathrm{M}_{\mathrm{EQ}}$ é a umidade de equilíbrio dinâmico.

Além do comportamento da retirada de umidade, tanto o resíduo in natura (antes da desidratação) quanto o resíduo desidratado passaram por uma série de análises físicoquimicas para avaliar a presença de compostos bioativos e antioxidantes nos mesmos. Foram verificados o teor de Flavonóides Totais(determinado pelo método colorimétrico descrito por Zhishen et.al 1999 e expressos em mg de rutina/100 g de amostra em base seca), teor de Fenólicos Totais (determinado pelo método de Folin Ciocalteau Singleton \& Rossi, 1965 e expresso em $\mathrm{mg}$ de ácido gálico/100 g de amostra em base seca), teor de Acidez Total Titulável (ATT)(através da titulação com $\mathrm{NaOH}$ e expresso por $\mathrm{mg}$ de ácido cítrico/100 g de amostra em base seca - AOAC, 1995) e teor de Ácido Ascórbico (AA) ou Vitamina C(obtido por titulometria, através da redução do 2,6-diclorofenol-indofenol, com os resultados expressos em $\mathrm{mg}$ de ácido ascórbico/100 g de amostra em base seca - AOAC, 1995). A umidade final das amostras foi calculada através do método da estufa a $105^{\circ} \mathrm{C} \pm 3{ }^{\circ} \mathrm{C}$ por 24 horas.

\section{RESULTADOS E DISCUSSÃO}

Primeiramente analisou-se os resultados de umidade e compostos bioativos para o composto in natura, que serviu como base de comparação:

Tabela 2 - Resultados para o Resíduo In Natura

\begin{tabular}{|c|c|}
\hline ANÁLISE & RESULTADO \\
\hline Umidade & $82,9 \pm 2,3 \%$ \\
\hline Teor de Flavonóides & $0,45 \mathrm{mg}$ rutina/ $100 \mathrm{~g}$ sólido seco \\
\hline Teor de Fenólicos & $122,13 \mathrm{mg}$ ácido gálico $/ 100 \mathrm{~g}$ sólido seco \\
\hline Teor de Acidez & $2701,35 \mathrm{mg}$ ácido cítrico $/ 100 \mathrm{~g}$ sólido seco \\
\hline Teor de Vitamina C & $0,54 \mathrm{mg}$ ácido ascórbico $/ 100 \mathrm{~g}$ sólido seco \\
\hline
\end{tabular}

Após isso, realizou-se a desidratação do resíduo nas condições especificadas na seção anterior, obtendo as seguintes curvas de desidratação:

Figura 2 e 3 -Curvas de Desidratação para os Experimentos de 1 a 8 

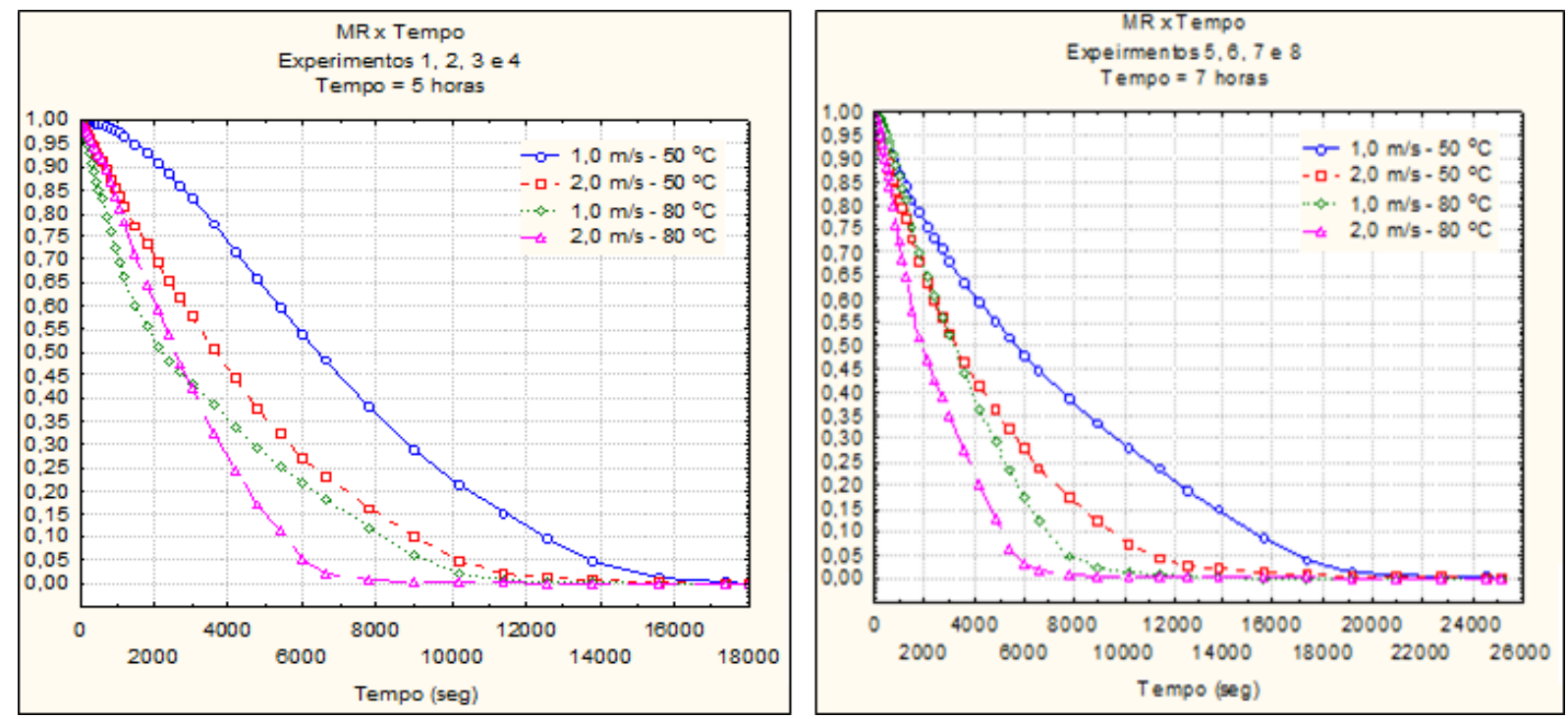

Analisando-se as curvas obtidas, pode-se observar que o aumento de velocidade e temperatura induzem a uma redução considerável no tempo de retirada de umidade, atingindo-se menores valores da mesma em menores intervalos de tempo. $\mathrm{O}$ aumento de temperatura possui um efeito ainda mais pronunciado nesse aspecto, o que pode ser confirmado pelos gráficos referentes aos experimentos $3,4,7$ e 8 .

Ao mesmo tempo, não há um efeito tão pronunciado quando analisamos a varíavel tempo, pois as curvas apresentaram praticamente o mesmo comportamento. Esse efeito é confirmado quando verificamos a umidade final obtida ao término de cada experimento, que foi respectivamente 6,$7 ; 6,9 ; 4,7 ; 6,4 \%$ para os experimentos de 1 a 4 e 6,$4 ; 5,3 ; 5,5$ e $3,1 \%$ para os experimentos de 1 a 8 , ou seja, pouca variação mesmo com o acréscimo de 2 horas de um conjunto de experimentos para outro.

Para os compostos bioativos, em comparação com o in natura obteve-se os seguintes resultados, expostos nas figuras 4, 5, 6 e 7:

Figuras 4 e 5 - Teor de Flavonóides e Fenólicos para os Experimentos de 1 a 8

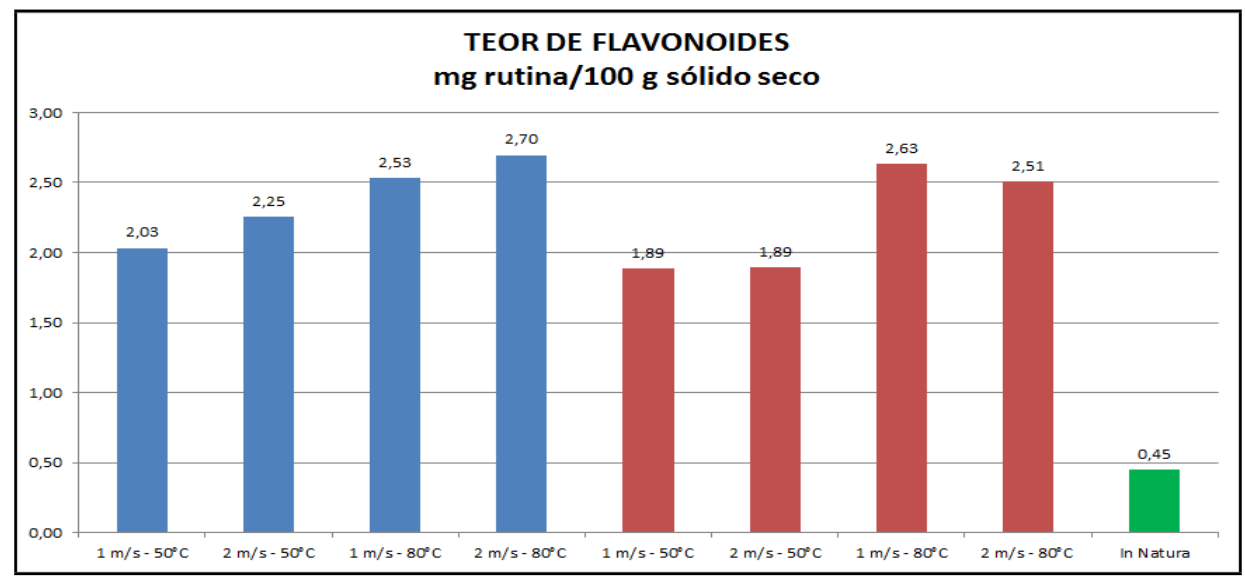




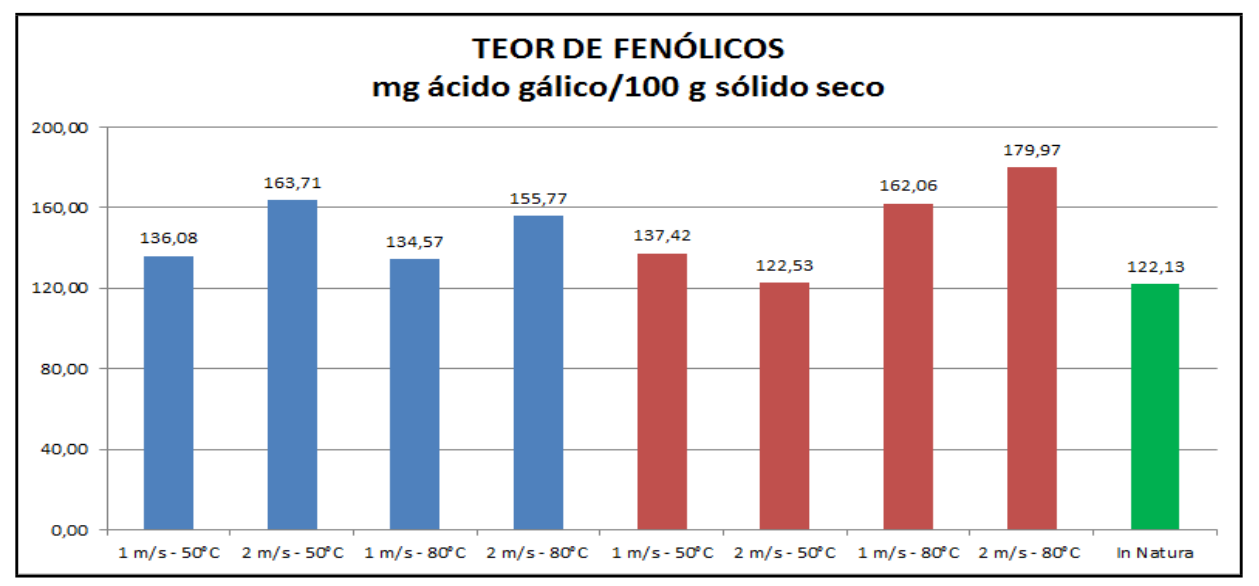

Analisando-se as figuras 4 e 5, verifica-se que em todos os experimentos realizados teores de flavonoides e fenólicos obtidos apresentaram aumento considerável em comparação com o resíduo in natura. Para tempos iguais a 5 horas (experimentos de 1 a 4), tal aumento se intensificou em velocidades maiores e ainda mais em temperaturas maiores. Já para tempos iguais a 7 horas (experimentos de 5 a 8), esse comportamento se manteve, mais de forma muito menos acentuada e em menores valores, o que indica degradação do composto por exposição prolongada ao ar quente.

Figuras 6 e 7 - Teor de Acidez e Vitamina C para os Experimentos de 1 a 8
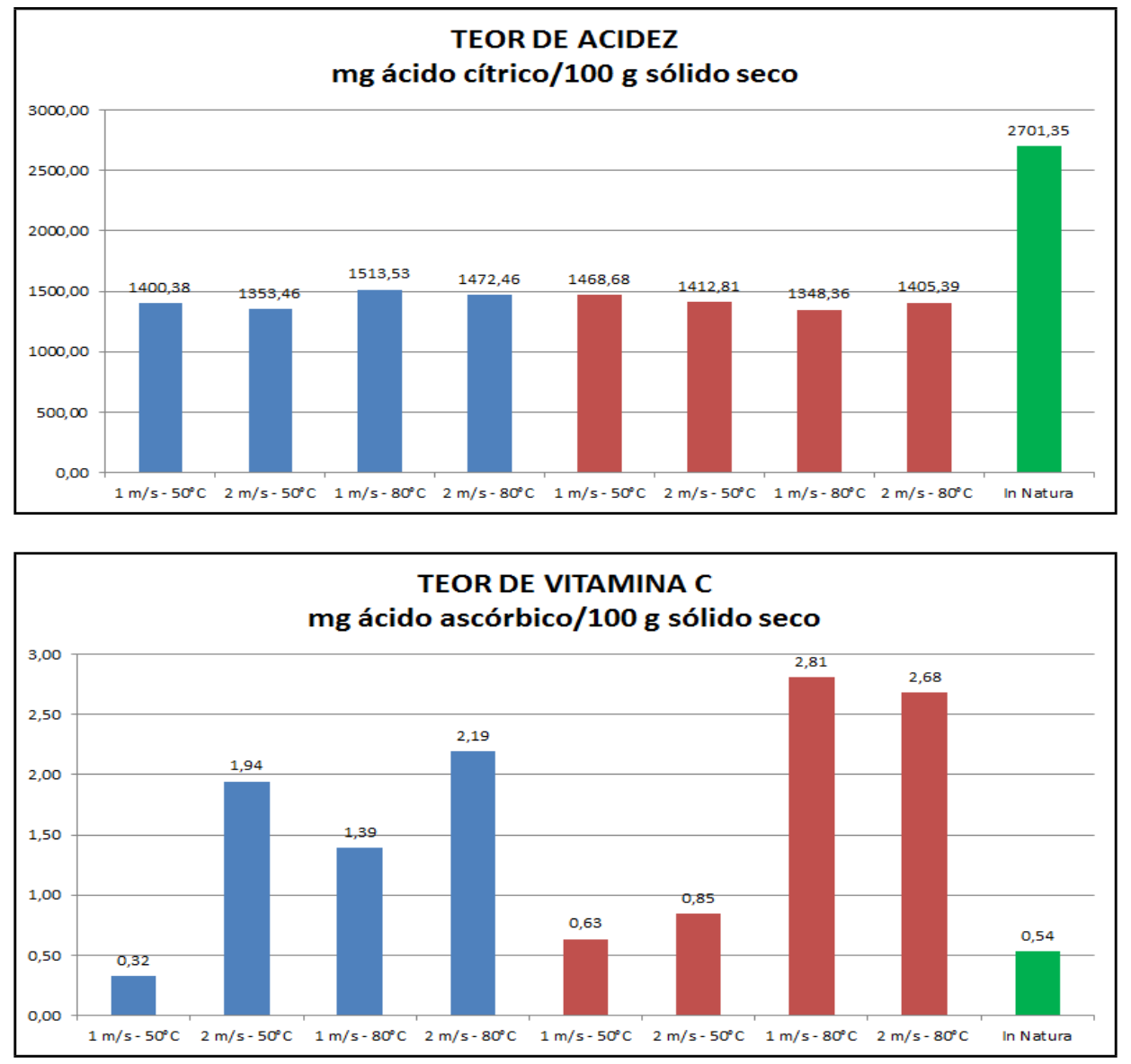
Já para os teores de Acidez e Vitamina C verificamos comportamentos distintos. Na Acidez, o valor praticamente muda muito pouco de um experimento para outro e todos os teores são inferiores a acidez do composto in natura, indicando degradação do ácido cítrico em todos os experimentos. Já para a Vitamina $\mathrm{C}$, obteve-se valores maiores que os do in natura, principalmente a temperaturas e tempos maiores de desidratação, $\mathrm{O}$ aumento de velocidade favoreceu esse comportamento na maioria dos experimentos também.

\section{CONCLUSÕES}

A desidratação de resíduos de processamento de maracujá utilizando ar quente mostrouse um método bastante satisfatório para a retirada de umidade desse material, sendo uma alternativa bastante viável para o tratamento e armazenamento desse resíduo para um posterior aproveitamento. As variáveis velocidade e temperatura se mostraram impactantes nesse processo, assim como, em menor escala, o tempo de exposição ao ar quente.

Somado-se a isso, tem-se o efeito positivo que esse método de desidratação apresentou para teores de compostos antioxidantes, onde para flavonoides, fenólicos e vitamina C obtevese um acréscimo no valor obtido quando comparado ao resíduo antes da desidratação. Apenas o teor de ácido cítrico obteve queda, o que não representa um problema, já que esse composto além de dar um sabor adstringente ao material (limitando seu reaproveitamento como reforço alimentar por exemplo), ele pode ser adicionado posteriormente ao processo.

\section{REFERENCIAS}

AOAC - Official Methods of Analysis Association of Official Analytical Chemists. Gaithersburg, MD: Association of Analytical Communities, 1995;

BARTHOLO, G. F. Perdas e qualidade preocupam. Informe Agropecuário, Belo Horizonte, V.17, n. 179, p.3. 1994.

DUZZIONI, A. G.; LENTON, V. M.; SILVA, D. I. S.; BARROZO, M. A. S., Effect of Drying Kinetics on Main Bioactive Compounds and Antioxidant Activity of Acerola (Malpighia emarginata D.C.) residue, International Journal of Food Science and Technology, v. 48, p. 1041-1047, 2013;

MATIAS, M. F. O.; OLIVEIRA, E. L.; GERTRUDES, E.; MAGALHÂES, M.A. Use of fibres obtained from the cashew (Anacardium ocidentale, L) and guava (Psidiumguayava) fruits for enrichment of food products. Brazilian Archives of Biology and Technology, Curitiba, 48:143-150, 2005.

SINGLETON, V. L \& ROSSI, J. A., Colorimetry of Total Phenolics with Phosphomolibidic Phosphotungistic Acid Reagents. American Journal of Enology and Viticulture, v. 16, p. 144-158, 1965;

ZHISHEN, J.; MENGCHENG, T.; JIANMING, W., The Determination of Flavonoid Contents in Mulberry and Their Scavenging Effects on Superoxide Radicals. Food Chemistry, v. 64, p. 555-559, 1999. 